\title{
Biblioteconomia e Ciência da Informação (BCI) como Filosofia da Informação Aplicada: uma reavaliação ${ }^{1}$
}

\author{
On defining library and information science as applied philosophy of information
}

\begin{abstract}
Luciano Floridi
$\mathrm{PhD}$ em Filosofia da Lógica pela Universidade Warwick, Inglaterra Pesquisador em Filosofia da Informação do Departamento de Filosofia da Universidade de Hertfordshire, Inglaterra

E-mail: 1.floridi@herts.ac.uk
\end{abstract}

\begin{abstract}
Resumo
O autor responde às críticas feitas a sua proposta de que a Filosofia da Information (FI) deveria substituir a Epistemologia Social como uma disciplina filosófica que melhor atende os fundamentos conceituais para a Biblioteconomia e Ciência da Informação (BCI). Sugere que a crise de identidade por que tem passado a BCI é o resultado natural de uma busca justificada mas ociosa por uma parceria filosófica que emergiu só recentemente: nomeadamente, FI. O desenvolvimento da BCI não deveria depender de uma teoria emprestada e empacotada. Como filosofia aplicada FI,a BCI pode produtivamente contribuir para o crescimento da pesquisa teóricabásica em FI e assim, promover seus próprios fundamentos.
\end{abstract}

Palavras-chave: Filosofia da informação, Epistemologia social, Biblioteconomia e ciência da informação.

\begin{abstract}
The author replies critics to his hypothesis that Philosophy of Information (PI) should replace Socal Epistemology as the philosophical discipline that can best provide the conceptual foundation for Library and Information Science (LIS). It is suggested that the 'identity' crisis undergone by LIS has been the natural outcome of a justified but precocious search for a philosophical counterpart that has emerged only recently: namely, PI. The development of LIS should not rely on some borrowed, pre-packaged theory. As applied PI, LIS can fruitfully contribute to the growth of basic theoretical research in PI itself and thus provide its own foundation
\end{abstract}

Keywords: philosophy of information, social epistemology, library and information science.

\footnotetext{
${ }^{1}$ Floridi, Luciano. "LIS as Applied Philosophy of Information: A Reappraisal". Library Trends 52:3 (2004), 658665. () 2004 The Board of Trustees of the University of Illinois. Translated and published online with permission of The Johns Hopkins University Press.

Este texto publicado na revista Library Trends versa sobre outro texto do autor publicado na revista Social Epistemology, a saber: On defining library and information science as applied philosophy of information. Social Epistemology, 2002 16(1), 37
}

InCID: R. Ci. Inf. e Doc., Ribeirão Preto, v. 1, n. 2, p. 37-47, jul./dez. 2010. 
A Biblioteconomia e a Ciência da Informação (BCI) deveriam desenvolver suas fundamentações teóricas em termos de uma filosofia da informação (FI). Esta sugestão pode parecer pouco inofensiva, a princípio. Onde mais, a ciência da informação poderia buscar fundamentos conceituais, se não em uma filosofia da informação? Entretanto, aceitar esta proposta, significa afastar-se de uma das poucas alternativas sólidas atualmente disponíveis no campo, nomeadamente, aquela que fundamenta a BCI com base em uma epistemologia social (ES). Não se trata de um deslocamento banal, portanto, é razoável que haja certa relutância. Para superar isso, a proposta mais do que aceitável, precisa ser convincente. Em um artigo anterior (FLORIDI, 2002a), articulei algumas das razões pelas quais acredito que a FI pode oferecer as fundamentações necessárias à BCI, melhor do que a Epistemologia Social. Não pretendo repetir os argumentos neste artigo. Apesar de considerá-los argumentos convincentes, estou pronto para mudar meus conceitos caso surjam argumentos contrários suficientes. Nesta oportunidade, gostaria de esclarecer alguns aspectos da minha proposta (FLORIDI, 2002a) em favor da interpretação da BCI como filosofia aplicada à informação. O esforço não será o de demonstrar minha correção ao sugerir que a FI pode fornecer uma fundamentação melhor para a BCI do que a epistemologia social. Meu objetivo, mais modesto, é o de eliminar algumas ambigüidades e eventuais mal-entendidos que possam impedir a avaliação correta desta minha posição, de modo que as divergências possam se tornar mais construtivas.

Freqüentemente, ouvimos falar sobre as diferenças entre o bibliotecário tradicional envolvido ativamente na gestão e na prestação de serviços públicos - e o cientista ou o especialista em ciência da informação que se dedica às respectivas especulações teóricas. A linha de raciocínio aqui é aquela que afirma que uma fundamentação para a BCI deva satisfazer ambos profissionais e que isso é algo que a FI não pode alcançar, por não ser "suficientemente" social. $\mathrm{Eu}$ aceito esta inferência, mas discordo da premissa. Penso que devamos distinguir, tão claro quanto possível, três níveis principais.

Existe um primeiro nível, onde lidamos com as bibliotecas, seus conteúdos e serviços. Compare isso com a atividade do contador, seus cálculos e procedimentos financeiros. Alguém pode querer desenvolver uma teoria da matemática cotidiana $\mathrm{e}$ de suas práticas sociais, sem dúvidas, este seria um trabalho digno e interessante, mas parece impossível confundir esse procedimento com o estudo da matemática do ponto de vista de uma ciência 
formal. O que já seria um segundo nível. Neste segundo nível está o papel da BCI, aquilo que se aprende com diferentes graus de complexidade durante o currículo acadêmico na formação do bibliotecário ou do cientista da informação. Aparece então um terceiro nível no qual somente uma minoria está interessada. Nós chamamos este nível fundacional. Na matemática trata-se da filosofia da matemática. Eu sugeri FI para a BCI. Meu argumento aqui é que seria importante reconhecer e respeitar a distinção entre esses três níveis; de outra forma alguém pode criticar $\mathrm{x}$ por não oferecer y quando x não está, a princípio lá, para oferecer y. Quando o banco me cobra muito caro por um saldo descoberto, você não necessita realizar uma análise aritmética, baseada nos axiomas de Peano. Da mesma forma, um cientista pode ficar satisfeito com o entendimento claro de estatística, sem desejar entrar no debate filosófico dos fundamentos da teoria da probabilidade. Assim, eu não vejo porque a BCI não possa conter uma abordagem teórica, capaz de remeter a problemas do profissional do dia-a-dia e do especialista, problemas que ambos, profissionais e especialistas, julgariam muito abstrato para merecer atenção nas práticas cotidianas (lembrar que estou falando sobre níveis, não pessoas; alguém pode usar o chapéu diferente em diferentes contextos). No final eu concordo que a FI deveria procurar explicar espectro amplo de fenômenos práticos. Ainda diria que esse é exatamente o desafio que se afigura. O escopo da FI inclui uma enorme variedade de práticas precisamente porque o seu objetivo é fundacionalista.

Se assumirmos, por um momento, a BCI como uma filosofia da informação aplicada, e a filosofia da informação como fundamentação conceitual adequada à BCI, a próxima questão é como, especificamente, a FI e a BCI podem interagir. Este ponto demonstra o tipo de investigações frutíferas que surgem de uma abordagem em FI em sua interface com a BCI. Outros três exemplos podem ilustrar melhor esse argumento e jogar luz sobre o debate da Epistemologia Social versus a FI. A filosofia da informação como fundamentação da BCI, trabalharia a principio com a ontologia dos 'objetos' da BCI, com uma teoria substancial da dinâmica da informação e uma abordagem ética do domínio da informação. Falarei mais sobre cada uma desses tópicos a seguir, mas quero enfatizar aqui que se o leitor considera essas áreas importantes, pode-se também admitir que elas caiam no escopo de qualquer abordagem da Epistemologia Social (ES). Mas por ora, vamos retornar à Filosofia da Informação.

InCID: R. Ci. Inf. e Doc., Ribeirão Preto, v. 1, n. 2, p. 37-47, jul./dez. 2010. 
Uma maneira simples de introduzir a FI seria referir-se a ela com a disciplina filosófica que tenta responder a questão "o que é a informação". Eu entendo que esta questão em si pode ser cansativa, até porque não há uma maneira simples de respondê-la, apesar da sua aparente simplicidade. Movimentos tradicionais e ordinários como checar num dicionário, consultar uma enciclopédia, observar uma pesquisa de opinião, cotejar citações não dão conta de responder essa pergunta e isto acontece não somente porque somos nós mesmos que escrevemos essas fontes. Imaginem tentar responder perguntas como "o que é a vida", "o que é a mente", "o que é o "significado". Perguntas ou questões como estas sempre abrem diálogos e provocam pesquisas capazes de manter gerações de cientistas ocupados. Essas perguntas são como sinal de trânsito que indicam como devemos nos movimentar. Reclamar sobre a falta de respostas precisas não faz sentido. As perguntas às questões filosóficas são inevitavelmente abertas. É necessário que as deixemos para trás para seguirmos em frente.

Informação é um tópico escorregadio. Isto explica a sua pertinência filosófica, mas não justifica um tratamento descuidado. Ao contrário. Antes que tentemos nossos primeiros passos nesse terreno movediço, é importante ter certeza de que dispomos de ferramental para ultrapassálo. Aqui entra a análise conceitual que pode nos ajudar a entender o próximo item.

É vital dar-se conta de que não existe uma teoria unificada da informação. Mesmo as pessoas que pensam de outra forma, reconheceriam que não faz sentido procurar uma única definição satisfatória para alimento em geral, e precisamos levar em conta que temos uma idéia de alimento muito melhor do que seja a informação. O que precisamos é de análise, análise e mais análise.

Neste ponto devemos ficar alertas, para não incorrermos no erro contrário, ou seja, sabendo que não há uma teoria unificada da informação, pensar que não há teoria qualquer possível. Errado. Abandonar a procura de uma teoria unificada da informação significa desistir da possibilidade da existência de um $U r$-conceito ${ }^{2}$ da informação, na raiz de uma reconstrução hierárquica multi-fatorial do fenômeno da informação. Mas, como já argumentei (2003a) os vários sentidos, usos, aplicações e tipos de informação, incluindo os fenômenos relacionados no ambiente, ainda podem ser interpretados como um sistema gravitacional em torno de uma noção nuclear, que contem uma prioridade teórica. A noção nuclear funciona como um dispositivo

\footnotetext{
${ }^{2}$ NT: Ur-conceito refere a um conceito superior

InCID: R. Ci. Inf. e Doc., Ribeirão Preto, v. 1, n. 2, p. 37-47, jul./dez. 2010.
} 
hermenêutico que influencia, interrelaciona e ajuda a acessar outras noções. Na FI esse papel central tem sido realizado por muito tempo, através de uma orientação epistemológica da informação. A idéia básica é simples. Para entender o que é informação, a melhor coisa a fazer, é começar analisando-a, em termos do conhecimento que pode surgir deste campo. A informação factual é o sentido mais importante da informação qua informação, para usar uma expressão aristotélica. Entretanto, duvido muito (talvez eu devesse ser mais honesto e declarar que não acredito de forma alguma nisso) que qualquer tentativa de sucesso pode ser obtida, reduzindo todos os outros conceitos à informação factual. Informação factual é como a capital de arquipélagos informacionais, estrategicamente posicionados, para oferecer uma compreensão clara do que é informação, e ter assim, uma ponte para outros conceitos que são interconectados, mas não necessariamente a um único $U r$-conceito. O modelo correto não é hierárquico, mas uma rede de conceitos conectados, ligados por influências mútuas e dinâmicas, não necessariamente genéticas ou genealógicas.

Deveria ficar claro do que foi dito, que não penso haver um único conceito da informação; que não assumo um conceito da informação, baseado na comunicação; que sou cético quanto à uma teoria unificada da informação, baseada em qualquer conceito privilegiado (incluindo a teoria da informação de Shannon); longe de mim, argumentar, a necessidade de uma filosofia digital da informação, por causa da revolução da tecnologia da informação e da virada computacional, embora essa última, certamente, pressionou a necessidade de uma FI, tornando-a premente; considero a Filosofia da Informação profundamente preocupada com a dinâmica lógica e histórica da informação, bem como com sua análise conceitual. Em outra oportunidade (2002c) enfatizei a importância de se reinterpretar vários episódios na história da filosofia à luz do novo paradigma informacional. E em outro artigo (2002b) tentei aplicar a análise histórica à transmissão de um corpus específico de texto.

Outra tese com a qual não concordo, diz respeito à existência da informação no mundo. Não sou ingênuo nem um realista crítico, mas também não sou um anti-realista (o bom da Filosofia da Informação é que ela ajuda a eliminar as velhas dicotomias). A posição que tenho desenvolvido é que a informação compreende dados que estão no mundo, independentemente de agentes epistêmicos. Os dados são melhor vistos como permissões restritivas (constraining affordancess), isto é, diferenças que convidam ou facilitam certas interpretações, em relação a 
processadores de dados inteligentes como nós, enquanto impedem ou tornam mais difícil alguns outros. "Onde", então está a informação? Uma analogia pode ajudar na resposta correta. Você diria que não há alimento no universo, a menos que haja consumidores para esse alimento? É claro que não. Mesmo que não haja uma forma de vida no planeta $\mathrm{Z}$, ainda pode existir alguns nutrientes, digamos minerais, água, que poderiam sustentar alguma forma de vida no planeta $\mathrm{Z}$. Por outro lado, grama é alimento somente para os herbívoros. Para um gato seria tão bom quanto um pedaço de plástico. Mutatis mutandes podemos argumentar que uma radiografia é uma peça de informação sobre meus pulmões, somente para alguém que possa interpretá-la. Alguém pode objetar que, interpretar a radiografia, é somente uma maneira de detectar uma peça de informação relevante no ambiente. Onde deveríamos colocar a "informação"? O debate sobre locus informationes tem sido uma tensão entre internalistas e externalistas. Algumas pessoas colocam a informação "dentro" da mente (a interpretação do radiologista da chapa dos meus pulmões); outros insistem que está no mundo (o estado dos meus pulmões representado na radiografia). Esta é uma discussão sem sentido. Quando consideramos o alimento, é claro que o alimento não está nem no mundo, como meros nutrientes, nem somente como uma função do sistema digestivo do consumidor. Da mesma forma, a informação semântica em geral é uma dessas "coisas bidimensionais" que não estão nem aqui nem lá, mas na interface entre nós e o ambiente, como um limiar ou limite entre os dois espaços. Eles são fenômenos relacionais. A conceituação "limítrofe" da informação não é redutível à formas de externalismo (naturalização da informação) ou internalismo (informação na mente do portador), sou minimalista, se isto pode ser um rótulo. Prefiro o rótulo ligado a um anfíbio, ontologicamente (ontologically amphibious). Seria então "liminalismo" somente uma outra forma de anti-realismo? A resposta depende do que se entende por anti-realismo, o que requer explicações mais detalhadas. Quando os dados adquirem significado, temos o que os filósofos da linguagem chamam "conteúdo". Em outros dois artigos (no prelo a e b) defendo o ponto de vista de que, para ter informação factual, é necessário dados significativos (conteúdo) que sejam também verdadeiros. Dois pontos precisam de esclarecimento aqui: primeiro, conteúdo é uma condição necessária para o conhecimento mas não é a única. Conhecimento significa algo muito preciso em epistemologia: é um conteúdo que seja ao menos verdadeiro (epistemólogos falam de crenças verdadeiras) e possivelmente justificado, isto é, apoiado por boas razões. A análise do conhecimento como crença verdadeira justificada não é satisfatória (FLORIDI, no prelo d), mas isto não é razão para pensar que possamos fazê-lo

InCID: R. Ci. Inf. e Doc., Ribeirão Preto, v. 1, n. 2, p. 37-47, jul./dez. 2010. 
sem a condição de verdade. Falar de um "falso conhecimento" não faz sentido. Exatamente como falar de "solteirões casados". Ninguém pode conhecer a Terra como plana, pelo simples fato que ela não é. Mas apesar disso, as bibliotecas estão cheias de falso conhecimento. Portanto, falar da BCI como uma disciplina preocupada com o conhecimento, ao invés do conteúdo é ao menos, impreciso e na pior das hipóteses, incorreto. BCI lida com conteúdos entendidos como dados significativos. Isto não tem nada a ver com manipulação mecânica de dados e manejo de bites. Mais do que isso, Biblioteconommia e Ciência da Informação estão relacionadas com atividades de um ambiente semântico.

O segundo ponto diz respeito a um comprometimento com uma teoria correspondentista ${ }^{3}$ da verdade. Disse acima que não acho que deveríamos privilegiar um conceito de informação baseado na comunicação. A alternativa usual - outra tentativa dicotômica novamente - é analisar a informação, em termos de sua contribuição representacional. Isso significa, eu acreditar, que a informação representa o mundo, pelo menos em alguns casos? Nem tanto, pois eu considero que esta não é a pergunta a ser feita. Tenho a compreensão, nem muito comum, nem popular entre os filósofos, que a semantização do dado é um processo de modelação em algum nível de abstração (NA). Não há espaço aqui para explicar a metodologia dos Níveis de Abstração (NAs) (FLORIDI \& SANDERS, no prelo - B), mas podemos ter uma idéia, considerando que, de acordo com a metodologia, qualquer acesso ao dado (e, portanto, qualquer acesso a qualquer aspecto do mundo), sob consideração, é mediado por um comprometimento ontológico, a um nível de abstração que pode ser, grosseiramente entendido, como uma interface. Por exemplo, nós somos agentes epistêmicos, inevitavelmente comprometidos com uma noção de espaço euclidiano. Agora, a função primária da informação factual parece ser o projeto, pelos agentes que o habitam, de um ambiente tão significativo quanto os próprios agentes. Somente parte desta sistematização é adaptada. A maior parte é "supérflua". Novamente, não me entendam mal: eu são estou sustentando a tese de que a "adaptação é bela". Muito pelo contrário, o segredo do nosso lugar especial no mundo me parece estar, exatamente, no nosso distanciamento "supérfluo" em relação ao mundo, causado pelo excesso de sentido que dispendemos, mais do que necessário,

\footnotetext{
${ }^{3}$ NT Teoria correspondentista da verdade é aquela que afirma que $\mathrm{x}$ é verdadeiro se $\mathrm{x}$ corresponde a um fato. Como fato também precisa ser definido, e para tal tem-se que recorrer à noção de verdade, cai-se num círculo vicioso; normalmente a teoria da coerência é apontada como uma saída para o impasse, já que ela coteja a consistência dos elementos das crenças, uns com os outros, numa rede de crenças. Na teoria correspondentista há cotejo de elementos heterogêneos (eunciados e fatos); na teoria coerentista há cotejo de elementos homogêneos (enunciados e enunciados, crenças e crenças).
}

InCID: R. Ci. Inf. e Doc., Ribeirão Preto, v. 1, n. 2, p. 37-47, jul./dez. 2010. 
para sobrevivermos como espécie. Somos animais que super-semantizamos e sem nenhum propósito de sobrevivência. Mas voltemos ao assunto realista. Nós construímos nossa compreensão do mundo tomando plena vantagem das permissões com restrições (dados) oferecidas por fontes externas, em diferentes níveis de abstração. Certamente os dados apenas sugerem a escolha de um nível particular de abstração, e a natureza do seu resultado, mas esta sugestão não é boleana e é inversamente proporcional ao grau de coerência entre os nossos níveis de abstração. Considere a seguinte analogia cruzada. Normalmente, uma palavra cruzada é um quebra-cabeça de duas dimensões, mas podemos facilmente imaginar uma versão com três dimensões (um cubo) no qual a coerência entre as linhas é ainda mais difícil de se obter. Agora, considere uma versão de $n$ dimensões, sendo $n$ tão grande quanto possamos imaginar. Por exemplo, uma palavra cruzada com quatro dimensões teria que satisfazer as restrições que também regulam as diagonais do cubo, e assim por diante. É isto que chamo de intercoerência multidimensional entre os níveis de abstração.

A coerência entre os NAs, entretanto, pode ainda garantir, algum tipo de realismo “interno" se esquecermos que a natureza dos observadores é também determinada, parcialmente, pelo dado sendo modelado. Se empírico, ou conceitual, os dados permitem somente um certo espectro de modelo, e nem todos os modelos são igualmente factíveis. Outra analogia pode ajudar aqui. Suponha que você tenha que construir um abrigo. O projeto e a complexidade do abrigo podem variar, mas há um espectro de possibilidades "realistas" limitado ou determinado pela natureza dos recursos disponíveis, objetivos, etc (tamanho, materiais de construção, localização, tempo, ambiente físico e biológico, força de trabalho, habilidades técnicas, propósitos, segurança, etc). Não é qualquer abrigo que pode ser construído e o tipo de construção, provavelmente, será aquela que se aproveitar melhor dos recursos disponíveis. O mesmo se aplica aos dados. Dados são recursos que tornam possível a construção de certos modelos e, os melhores modelos, são aqueles melhor adaptados às possibilidades permitidas (constraining affordances). Isto é o que chamo de adequação. Coerência e adequação não representam ingenuidade ou realismo direto, ou uma teoria correspondentista da verdade como é normalmente apresentada. Por último, níveis de abstração constroem modelos de sistemas de dados; eles não representam, ou fotografam, ou retratam, ou fotocopiam, ou mapeiam, ou espiam, ou mostram, ou revelam, ou monitoram, ou a natureza intrínseca dos sistemas que analisam, mais do que o iglu descreve a natureza intrínseca da neve, ou o Parthenon indica as propriedades reais 
das pedras. Nós nem descobrimos nem inventamos o mundo, nós o projetamos. Nós entendemos o mundo de forma derivativa, somente se entendemos seus modelos. Um mundo como uma experiência de todo dia é o resultado de modelação dos dados, dentro de um grau de coerência interna, de níveis de abstração, tão grande quanto desejarmos. Isto não é uma visão realista nem anti-realista, mas uma visão construcionista da informação.

Abordando a filosofia da informação, de uma perspectiva construcionista, significa adotar um horizonte metafísico (FLORIDI, no prelo c). E é desta perspectiva que a Ética da Informação (EI) deveria ser avaliada. Expliquei, em outros contextos, porque penso necessário desenvolver uma ética da infoesfera (FLORIDI, 1999; FLORIDI; SANDERS, 2001; FLORIDI; SANDERS, 2002; FLORIDI; SANDERS, no prelo a). Aqui só quero esclarecer um aparente mal entendido. Quando defendo um valor mínimo e substituível, intrínseco e moral dos objetos informacionais (FLORIDI, 2003b) não me refiro a um valor moral de um email, ou de um princípio de Newton, ou de qualquer outro trecho de dado significativo ou bem formado. Honestamente, seria muito ingênuo de minha parte. O que estou sugerindo é abordar a análise do Ser, informacionalmente, adotando uma ontologia mínima comum através da qual, os seres humanos, tanto quanto os animais, as plantas, os artefatos, são interpretados como entidades informacionais.

Espero que a analogia a seguir possa contribuir na compreensão. Mesmo que não seja justa a tese filosófica em curso. Imagine olhar o universo inteiro de um ponto de vista puramente químico: você é $70 \%$ água e $30 \%$ qualquer outra coisa. Agora considere um nível informacional de abstração. Você é $100 \%$ um conjunto de dados. Mais precisamente, você (como qualquer outra entidade) é um pacote discreto, auto-contido, encapsulado que contém 1) uma estrutura apropriada de dados que constitui a natureza da entidade em questão: estado do objeto, sua identidade única, seus atributos e 2) uma coleção de operações, funções ou procedimentos que são ativados por interações ou estímulos variados, nomeadamente mensagens recebidas de outros objetos ou mudanças dentro de si próprio, e que definem como o objeto responde ou reage a eles. Neste nível de abstração, objetos informacionais como tais, mais do que simplesmente sistemas vivos, em geral surgem no papel de pacientes de qualquer ação. A ética da informação é, então, somente uma evolução da ética ambiental. Seu princípio fundamental é que algo mais elementar que a vida, o Ser entendido informacionalmente e, portanto, algo mais fundamental que prazer ou dor, nomeadamente "entropia" (não o conceito físico de entropia; aqui significando, destruição de 
objetos informacionais, isto é, o Nada no vocabulário da antiga metafísica substancialista do Ser). De acordo com a ética da informação teríamos também que avaliar as obrigações dos agentes morais em termos da sua contribuição para o crescimento da infoesfera e qualquer processo, ou ação, ou evento que negativamente afeta toda a infoesfera - não somente o objeto informacional - como um aumento de seu nível de entropia e, portanto uma instância do mal. A questão ética levantada pela a Ética da Informação é "o que é bom para uma entidade informacional e para a infoesfera em geral?" A resposta é dada por uma teoria minimalista de desertos: qualquer entidade informacional é reconhecida como estando no centro de preocupação ética que merece reconhecimento e deveria ajudar a regular a implementação de qualquer processo informacional que o envolve, se possível. A aprovação ou desaprovação de qualquer processo informacional é então baseada em como a implementação de qualquer processo informacional afeta a essência de entidades informacionais que este processo envolve e, mais geralmente, toda a infoesfera, isto é, o quão bem ou mal sucedida é em respeitar os clamores éticos atribuíveis às entidades informacionais envolvidas e, portanto, em engrandecer ou empobrecer a infoesfera. A ética da informação resulta no processo de ampliar o conceito daquilo que deve ser a preocupação moral mínima, incluindo agora, cada entidade informacional. Claramente, a relação entre ética da informação e biblioteconomia e ciência da informação deveria merecer investigação.

\section{Agradecimentos}

Sou grato a Ken Herold por este convite em contribuir para este número especial da Library Trends. Ele e Matteo Turilli fizeram vários comentários úteis nos meus rascunhos. FI é uma área de pesquisa próspera. Limitei-me aqui a apontar uma lista de trabalhos em que a introduzi como novo campo filosófico e discuti suas fundações. As referências da literatura corrente menos centradas em Floridi podem ser encontradas nos trabalhos citados. Todos os artigos da bibliografia estão disponíveis em: http://www.wolfson.ox.ac.uk/ floridi/ under "publications and papers online

InCID: R. Ci. Inf. e Doc., Ribeirão Preto, v. 1, n. 2, p. 37-47, jul./dez. 2010. 


\section{Referências}

FLORIDI, L. Information ethics: on the theoretical foundations of computer ethics. Ethics and Information Technology, v. 1, n.1, p. 37-56, 1999.

On defining library and information science as applied philosophy of

information. Social Epistemology, v. 16, n. 1, p. 37-49, 2002a.

Sextus empiricus: the transmission and recovery of pyrrhonism. New York: Oxford University Press, 2002b.

2002c.

What is the philosophy of information? Metaphilosophy, v. 33, n. 1-2, p. 123-145,

Information. In: FLORIDI, L. (Ed.). The Blackwell guide to the philosophy of

computing and information. New York: Blackwell, 2003a. p. 40-61.

. On the intrinsic value of information objects and the infosphere. Ethics and

Information Technology, v. 4, n. 4, p. 287-304, 2003 b.

prelo a.

Is information meaningful data? Philosophy and Phenomenological Research. No

. Outline of a theory of strongly semantic information. Minds and Machines. No prelo b

. Two approaches to the philosophy of information. Minds and Machines. No prelo c.

. On the logical insolvability of the Gettier problem. Synthese. No prelo d.

FLORIDI, L., SANDERS, J. W. On the morality of artificial agents. In: COMPUTER ETHICS: PHILOSOPHICAL ENQUIRY, 4., 2001, Lancaster. Proceeding... Lancaster: Lancaster University, 2001.

Computer ethics: mapping the foundationalist debate. Ethics and Information

Technology , v. 4, n. 1, p. 1-9, 2002.

. Internet ethics: the constructionist values of Homo Poieticus. In: CAVALIER, R. (Ed.)

The impact of the Internet on our moral lives. Albany: SUNY, no prelo a.

. The method of abstraction. In: NEGROTTI, M. (Ed.). Yearbook of the artificial.

Nature, culture and technology. Models in contemporary sciences. Bern: Peter Lang, no prelo b.

Tradução: Solange Puntel Mostafa e Denise Viuniski da Nova Cruz

Artigo submetido em 22 nov. 2010

Artigo aceito em 15 dez. 2010

InCID: R. Ci. Inf. e Doc., Ribeirão Preto, v. 1, n. 2, p. 37-47, jul./dez. 2010. 